\section{Quality of life, work motivation, burn-out and stress perceptions benefits of a stress management program by autogenic training for emergency room staff: A pilot study}

\author{
Pasquale Caponnetto, ${ }^{1-3}$ \\ Rosanna Magro, ${ }^{1}$ Lucio Inguscio, ${ }^{4}$ \\ Maria Concetta Cannella 1
}

1 ASP3 CT, Catania, Italy; ${ }^{2}$ Department of Clinical and Experimental

Biomedicine, University of Catania, Italy; ${ }^{3}$ Institute of Social Marketing, University of Stirling, UK; ${ }^{4}$ Department of Psychology, University of Rome La Sapienza, Rome, Italy

\begin{abstract}
Emergency room have particularly stressful work situations. Emergency room personnel cope with stressors on a daily basis. These stressors can be risks factor for burn out and for reduced quality of life and work motivation. Emergency room staff of one of ASP 3 CT urban hospital in Acireale, Italy participated to stress management program by autogenic training twice a month for 16 weeks. This program were prepared based on existing research and studies, and were conducted by clinical psychologists. We found that the mean value in pre-test is significantly different from mean value in post-test for: Perceived Stress Scale PPS $(\mathrm{t}=7.72$ with $27 \mathrm{df}$ and $\mathrm{P}<0.001)$; Euro Quality for life ( $\mathrm{t}=-14,13$ with $27 \mathrm{df}$ and $\mathrm{P}<0.001$ ); Work motivation assessed by Visual Analogue scale VAS $(\mathrm{t}=-4.52$ with $27 \mathrm{df}$ and $\mathrm{P}<0.001$ ). In the Maslach Burnout Inventory, the mean value is significantly different for emotional exhaustion sub-scale ( $\mathrm{t}=5.64$ with 27 with $27 \mathrm{df}$ and $\mathrm{P}<0.001$ ) and for depersonalization subscale $(\mathrm{t}=6.67$ with $27 \mathrm{df}$ and $\mathrm{P}<0.001)$. No significant difference was observed for the personal accomplishment sub-scale. This research suggests that psychological interventions with emergency room staff are effective. Our study showed effectiveness of an autogenic and stress management training in improvement of quality of life, work motivation, burn-out and stress perceptions for emergency department team.
\end{abstract}

\section{Introduction}

Quality of life affects worker and customer satisfaction, as well as organizations' status, productivity, and endurance. It rests on the belief that people are the most important assets in any organization, and should be treated with dignity and care. ${ }^{1}$ There are a variety of stress factors in the workplace of healthcare workers that have been shown to raise the risk of distress and burnout such as increasing workload, emotional response to interaction with suffering and dying patients, and organisational problems and conflicts. $^{2}$ Burnout in turn negatively impacts quality of care, 3 which may ultimately lead to worse health outcomes in patients.

Quality of life of emergency staff experts can be effective in providing services to patients. ${ }^{4}$ Healthcare personnel can suffer from work-related or occupational stress as a result of organisational factors and an imbalance of demands, skills and/or social support at work. Under some conditions this can lead to severe psychosomatic diseases, distress, burnout and the resulting deterioration in quality of life and service provision. ${ }^{5}$

Emergency room have particularly stressful work situations. Emergency room personnel cope with stressors on a daily basis. ${ }^{6}$ These stressors can be risks factor for reduced quality of life. ${ }^{7}$ A recent qualitative review reported that emergency room physicians showed elevated difficult work conditions including significant psychological demands, lack of resources, and poor support. ${ }^{8}$ Another recent study showed that good quality of life could lead to good empathy, and vice versa, good quality of life and good empathy could lead to the better outcome in emergency care. ${ }^{9}$

Our research examined the impact of autogenic and stress management training in emergency room staff' quality of life, work motivation, burn-out and stress perception. Given this evidence, we were particularly interested to examine whether psychological interventions, as combining autogenic and stress management training, were related to quality of life, work motivation, burn-out and stress management improving, in emergency room personnel.

\section{Methodology}

\section{Participants}

Participants were physicians and nurses all employed in the S. Marta ASP 3 CT Emergency Room of an urban hospital in Acireale, CT, Italy.

All of 30 members of emergency room
Correspondence: Pasquale Caponnetto, Department of Educational Sciences, Università degli Studi di Catania, Piazza Università 2, 95131 Catania, Italy.

E-mail: pcapon@unict.it

Key words: stress management training, emergency room staff, quality of life, work motivation, burnout and stress perceptions.

Acknowledgments: The investigators are grateful to Dr. Marizio Platania, Dr. Maria Grazia Lauria, Dr. Sonia Mazzeppi, for their help during recruitment and assessments.

Contributions: the authors contributed equally.

Conflict of interest: the authors declare no potential conflict of interest.

Funding: none.

Received for publication: 20 October 2018. Accepted for publication: 13 November 2018.

This work is licensed under a Creative Commons Attribution-NonCommercial 4.0 International License (CC BY-NC 4.0).

(C) Copyright P. Caponnetto et al., 2018

Licensee PAGEPress, Italy

Mental Illness 2018; 10:7913

doi:10.4081/mi.2018.7913

personnel participated to screening visit and 28 participated to autogenic and stress management training, 66\% (female) 44\% (male) with 47.3 mean age (sd 8.06).

\section{Procedures}

All participants provided written consent for their data to be used in research. Data were collected via anonymous questionnaires that comprised demographic and work-related questions as well as measures of quality of life, work motivation, burn-out and stress perception. This study has been approved by local ethics committee

\section{Measures}

Participants completed psychological instruments at baseline and at end of program. Socio-demographic measures were assessed by self-report including age, gender and education. Burnout was assessed by the Maslach Burnout Inventory (MBI). ${ }^{10}$ Burnout has been defined as a psychological syndrome that comprises emotional exhaustion (i.e., depletion of emotional resources, being overextended and emotionally drained), a tendency to depersonalize encounters with clients reflecting a loss of concern and compassion towards others, 
and a diminished sense of personal achievement at work. ${ }^{11}$ The scale has 22 items that are answered on 6-point Likert scales and index the cumulative effects of work-related stressors on three dimensions including depersonalization, emotional exhaustion and sense of personal accomplishment. Higher scores for the first two scales and lower scores for the last one are indicative of burnout. The scale showed acceptable to good internal consistency for all three subscales. ${ }^{11}$

Stress were assessed by the Perceived Stress Scale (PSS). The PSS is the most widely used psychological instrument for measuring the perception of stress. It is a measure of the degree to which situations in one's life are appraised as stressful. ${ }^{12}$ The PSS was designed to determine the degree to which situations in one's life are appraised as stressful. 13 On the basis of the transactional model of stress and coping, the PSS was designed to measure the degree to which an individual believes his/her life has been unpredictable, uncontrollable and overloaded during the past month. ${ }^{13}$

Quality of life were assessed by EQ-5D, EQ Visual Analogue scale (EQ VAS) (EuroQol). ${ }^{14}$ The EQ VAS records the respondent's self-rated health on a $20 \mathrm{~cm}$ vertical, visual analogue scale with endpoints labelled 'the best health you can imagine' and 'the worst health you can imagine'. The EQ VAS scores are anchored on $100=$ the best health you can imagine and $0=$ the worst health you can imagine It is a standardized instrument for use as a generic measure of health outcome, quality of life.

Work motivation was assessed by a Visual Analogue Scale (VAS). This work motivation VAS records the respondent's self-rated health on a $20 \mathrm{~cm}$ vertical, visual analogue scale with endpoints labelled 'the best work motivation you can imagine' and 'the worst work motivation you can imagine. This work motivation VAS scores are anchored on $100=$ the best work motivation you can imagine and $0=$ the worst motivation you can imagine.

\section{Detailed programme description}

Stress management program by autogenic training was based on existing research and studies, and were conducted by clinical psychologists (researcher) in the form of eight 180-min sessions twice a month (Table 1). We excluded participants with previous negative experience of meditation and/or classic hypnosis, and with serious mental illness.

Autogenic training (AT) is a self-relaxation procedure by which a psychophysiological determined relaxation response is elicited. AT is based on passive concentration of bodily perceptions (e.g., heaviness and warmth of arms, legs, and abdomen; rhythm of breath; and heartbeat). Within the therapeutic sessions the task of the psychologists includes i) to evaluate disease models of the participants and to introduce the psychophysiological model of the effects of AT (or relaxation in general), ii) to reinforce positive relaxation responses reported by the participants after the exercises, iii) to deal with possible negative initial relaxation responses, and iv) to enhance motivation for training. 15 The AT consisted of supervised training session twice a monthsfor 16 weeks. The course of the AT was progressive. During the session number one, the clinical psychologists introduced the emergency room staff to AT. Origins of AT, potential psychophysical sensations, possible solutions and problems, and postural positions were discussed. During this day, the clinical psychologists introduced the participants to the first two formulas (heaviness and warmth in the limbs). At 2-week intervals, the physiologically oriented phrases relating to cardiac regulation (week 4), respiratory control (week 6 and 8), "plexus solaris"(week 10 and 12) and coolness of the forehead (week 14 and 16) were introduced. The participants were also asked to practice regularly (three times a day) for the intervention period and record their practice and experiences in a dedicated diary. Stress management program by autogenic training included also 8 sessions that the emergency room staff done also as home works. It was also based on standard principles of REBT (Rational EmotivBehavior Therapy) principles and includes several modules (stress information andreaction, stress assessment; deep respiration; cognitive re-structuration; acceptation; behavioral skills, time management, healthy behaviors, problem solving and emotion regulation).

\section{Data analytic strategy}

All analyses were performed in SPSS. We examined association between interventions for the four outcomes: Stress (PSS), Work Motivation (VAS), Burnout (MBI), and Quality of life and EQ-VAS (EuroQol). All analyses were performed using statistical software IBM Spss ver 24.

In this study, we performed analyses on single group at the initial stage of the study (pre-test) and in the post-test after the program. The measurements of the variables were carried out using a intervals scale, and they are part of the instruments in use (Perceived Stress Scale - a measured variable, Maslach Burnout Inventory with three sub-scales with a variable each, Euro Quality of Life with a measured variable;

\section{Table 1. Stress management program by autogenic training.}

First session (Week 0) Stress definition, stress cause, body response, effect of stress on care quality dimensions, introduction of stress management strategies. explanation of diaphragmatic respiration.

Origins of AT, psychophysical sensations, solutions and problems, postural positions. First two AT formulas (heaviness and warmth in the limbs).

\begin{tabular}{ll} 
Second session (Week 4) & $\begin{array}{l}\text { Coping with stress, importance of healthy nutrition, adequate sleep, and physical activity. } \\
\text { AT oriented phrases relating to cardiac regulation }\end{array}$ \\
\hline Third session (Week 6) & $\begin{array}{l}\text { The ABCD model (activating event, beliefs and self speech, emotional outcome). } \\
\text { AT respiratory control formula }\end{array}$ \\
Fourth session (Week 8) & $\begin{array}{l}\text { Familiarization with cognitive errors and negative automatic thoughts } \\
\text { AT respiratory control formula }\end{array}$ \\
\hline Fifth session (Week 10) & $\begin{array}{l}\text { Imagination, recognition of thoughts acceptance-rejection evidence, knowing replacing beliefs, thoughts examination } \\
\text { AT "plexus solaris" formula }\end{array}$ \\
Sixth session (Week 12) & $\begin{array}{l}\text { Education of problem-solving skill and its usage in stressful events } \\
\text { AT "plexus solaris" formula }\end{array}$ \\
\hline Seventh session (Week 14) & $\begin{array}{l}\text { Education of employed' efficient communication skills and its effect on care quality dimension } \\
\text { AT coolness of the forehead formula }\end{array}$ \\
Eight session (Week 16) & $\begin{array}{l}\text { Anger and its management, automatic thoughts and individuals' response. Develop personal stress management program } \\
\text { AT coolness of the forehead formula }\end{array}$ \\
\hline
\end{tabular}


Vas Motivation with a measured variable). Statistical analysis was conducted using a comparison of average single group values between the pre-test and the post-test phase. Using a one-sample $t$ test we saw if the mean difference score was significantly different from a constant. We used this logic to test whether the mean value before treat- ment was significantly different from the mean value after treatment. If the two means were equal, we would expect the difference between them to be zero. Therefore, we tested whether the two means were significantly different from each other by testing whether the mean of the difference variable was significantly different from zero.
We found that the mean value in pre-test was significantly different from mean value in post-test for: i) Perceived Stress Scale PPS ( $\mathrm{t}=7.72$ with $27 \mathrm{df}$ and $\mathrm{P}<0.001$ ) (Figure 1); ii) Euro Quality for life $(\mathrm{t}=$ 14,13 with 27 df and $\mathrm{P}<0.001$ ) (Figure 2); iii) Visual Analogue scale VAS ( $\mathrm{t}=-4.52$ with $27 \mathrm{df}$ and $\mathrm{P}<0.001$ ) (Figure 3); iv) In

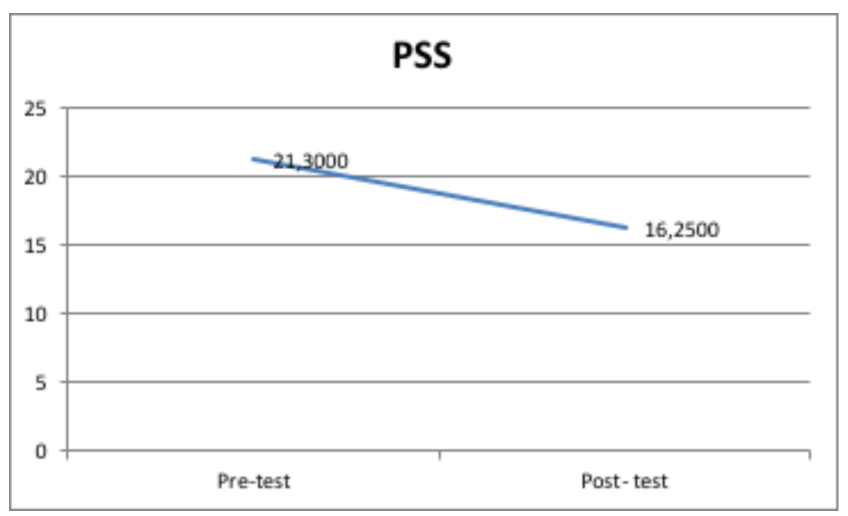

Figure 1. Mean value pre-post test in Perceived Stress Scale.

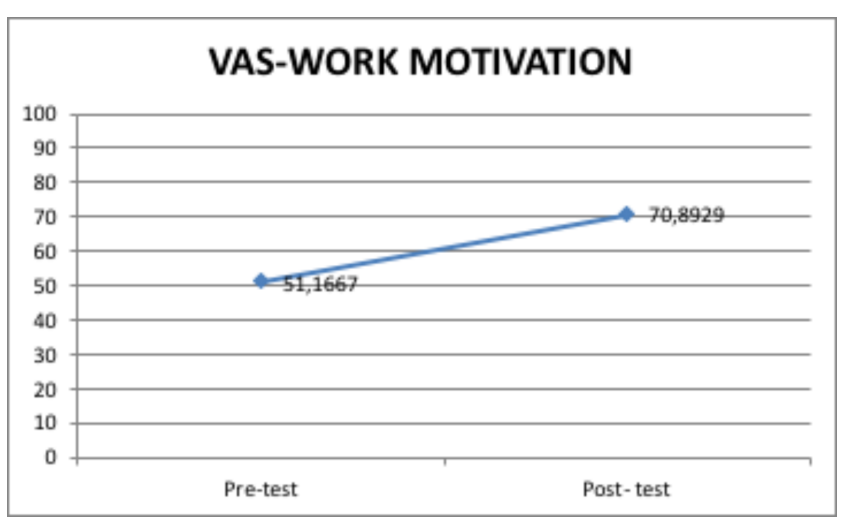

Figure 3. Mean value pre-post test VAS.

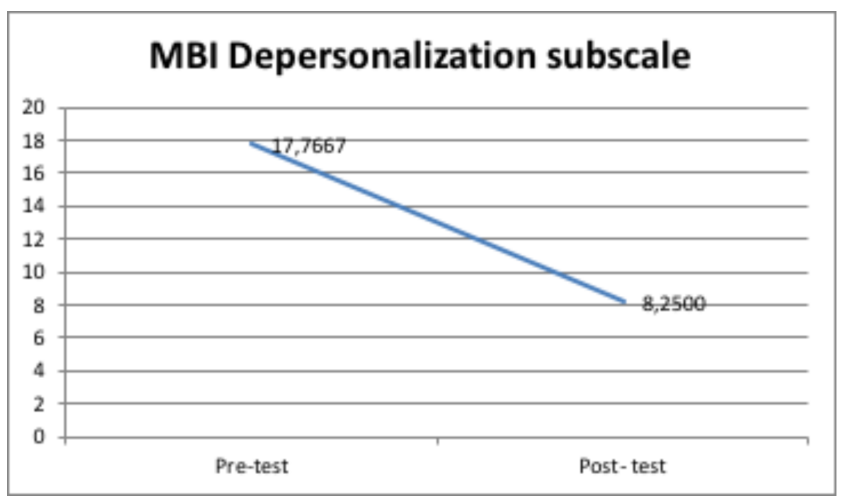

Figure 5. Mean value pre-post test Depersonalization subscale.

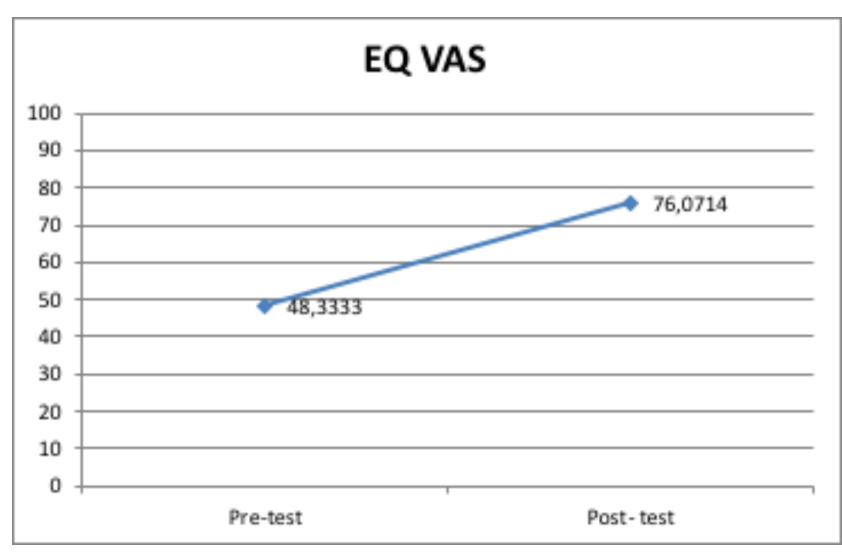

Figure 2. Mean value pre-post test EuroQuality for life.

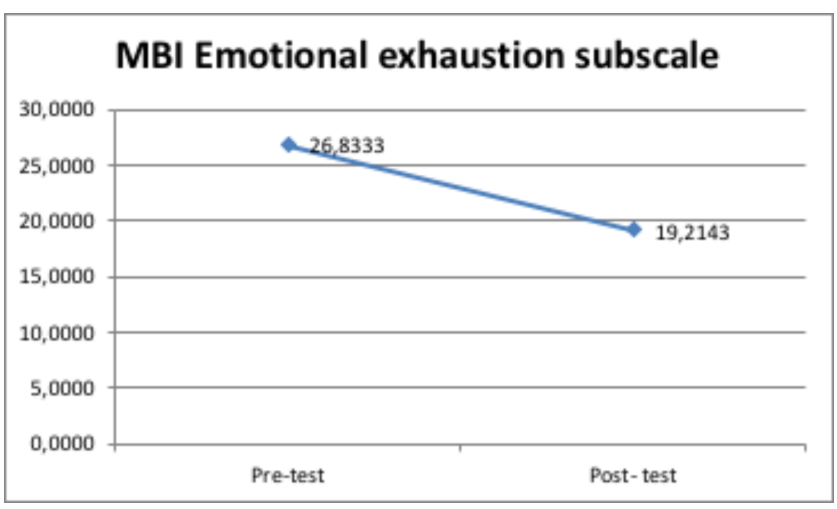

Figure 4. Mean value pre-post test Emotional exhaustion subscale.

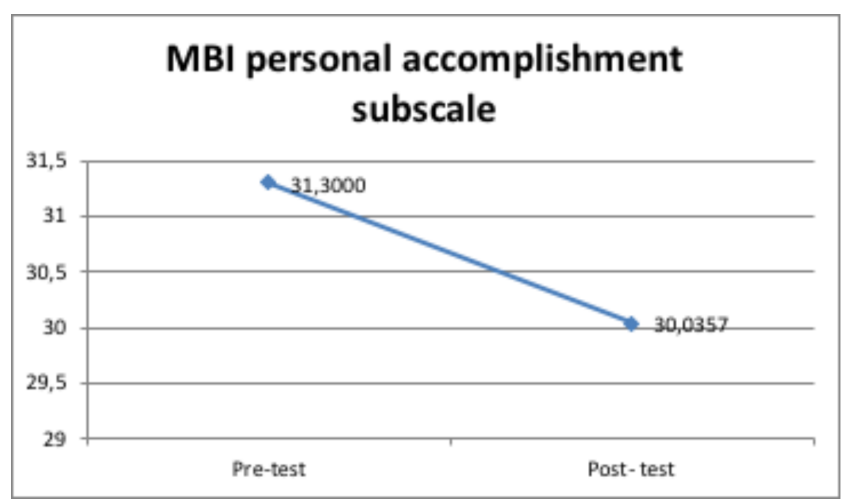

Figure 6. Mean value pre-post test personal accomplishment subscale. 
the Maslach Burnout Inventory, only for "emotional exhaustion" and "depersonalization" sub-scales the mean value are significantly different: a) Emotional exhaustion ( $\mathrm{t}=5.64$ with 27 with $27 \mathrm{df}$ and $\mathrm{P}<.001)$ (Figure 4); b) Depersonalization $(\mathrm{t}=6.67$ con 27 with $27 \mathrm{df}$ and $\mathrm{P}<.001$ ) (Figure 5); c) No significant difference for the personal accomplishment sub-scale (Figure 6). See also Supplementary Material for further details.

\section{Discussion and Conclusions}

With respect to what is found in the literature and what emerged from the results of the study, it can be confirmed that the first aid workers are among the most exposed working categories to stressful events, with many responsibilities and Intense working rhythms.

The quality of life of these health operators is particularly proven by the evident relational asymmetry that is established in the aid professions, in which contact with the user's suffering is continuous and ubiquitous and requires a capacity to take charge of the pain of others. ${ }^{16}$ Constantly, the physicians and nurses reported the complexity of the events they are to daily exposed (e.g. complex relationship with patients and families who are experiencing a situation of criticality, lack of psychological support and moments to reflect and communicate effectively).

It is therefore inevitable that these situations will affect on the psychological aspects analyzed in the study and on the quality of the medical-nursing services provided to the patient in terms of efficacy and efficiency. It also often results in an exponential increase in the costs of the company in terms of the absence of disease and the decrease in productivity and, more and more frequently, in episodes of aggression. All these events, underline even more clearly the need to support the operators in the daily management of stress, fears, motivation.

The statistical analysis, although based on a limited sample emphasize therefore not only the validity of this program but also the need to experience the same program, during each new working year. Moreover, given the positive feedback of this intervention in terms of decreased stress, increased motivation, decreased risk indexes for the development of burn-outs and improvement of the quality of life, It would be said that the implementation of this program would also diminish the economic impacts to which a hospital company is to be met, which are generally derived from the described situations of discomfort at work, in terms of diseases, absences, poor quality of service.

Research strongly suggests that psychological interventions with emergency room staff are effective. Our study showed effectiveness of a stress management program by autogenic training in improvement of quality of life, work motivation, burn-out and stress perceptions for emergency room staff. Because of its design, there are a number of limitations that must be considered when interpreting the findings of this study (e.g the small sample size and absence of control group). Some characteristics of the sample limit generalization of the findings; all subjects, have high education level, the findings reported from urban Sicilian residents in this study may not be valid for other population samples. Nonetheless, our study indicated that stress management program by autogenic training is an inexpensive strategy that can be quite effective for allemergency room staff. This can represent a good starting point for new studies to improve psychological interventions foremergency room staff. Finally, for a future perspective, using the same measuring instruments we can see if there is a significant long-term effect in comparison to a control group.

\section{References}

1. Pablos P, Tennyson R. Strategic Approaches for Human Capital Management and Development in a Turbulent Economy. New York: Business Science IGI; 2014.

2. McNeely E. The consequences of job stress for nurses' health: Time Outcome Studies. Nurs Outlook 2005;53:291-9.

3. Poghosyan L, Clarke SP, Finlayson M, Aiken LH. Nurse burnout and quality of care: cross-national investigation in six countries. Res Nurs Health 2010;33:288-98.

4. Amini A, Munesan MR, Kariman H, Dolatabadi AA. Quality of Life in Emergency Medicine Specialists of
Teaching Hospital, 2014. Emerg (Tehran) 2014;2:134-7.

5. Weinberg A, Creed F. Stress and psychiatric disorder in healthcare. Lancet 2000;355:533-7.

6. Josland H. Stress and stress management. In: Dolan B, Holt L, eds. Accident and emergency: theory into practice. London: Elsevier; 2008.

7. Freudenberger HJ. Staff burnout. J Soc Issues 1974;30:159-65.

8. Bragard I, Dupuis G, Fleet R. Quality of work life, burnout, and stress in emergency department physicians: a qualitative review. Eur J Emerg Med 2015;22: 227-34.

9. Seo JW, Park KH, Park HY,e t al. Empathy and Quality of Life in Korean Emergency Physicians. J Kor Soc Emerg Med 2016;27:150-6.

10. Maslach C, Jackson SE., Leiter MP. MBI: The Maslach Burnout Inventory: Manual. Palo Alto, CA: Consulting Psychologists Press; 1996.

11. Maslach C. Burnout: The Cost of Caring. Prentice Hall, NJ: Englewood Cliffs; 1982.

12. Cohen S, Kamarch T, Mermelstein R. A global measure of perceived stress. J Health Soc Behav 1983;24:385-96.

13. Cohen S, Williamson G. Perceived stress in a probability sample of the United States. In: Spacapan S, Oskamp $\mathrm{S}$, eds. The Social Psychology of Health: Claremont Symposium on Applied Social Psychology. Newbury Park: Sage; 1988. pp 31-67.

14. Van Hout B, Janssen MF, Feng YS, et al. Interim scoring for the EQ-5D-5L: mapping the EQ-5D-5L to EQ-5D-3L value sets. Value Health 2012;15:70815.

15. Stetter F, Kupper S. Autogenic training: a meta analysis of clinical outcome studies. Appl Psychophysiol Biofeedb 2002;27:4598.

16. Galati D, Fassio O, Viglino $M$. Motivazioni ed emozioni dei medici e degli infermieri del pronto soccorso. Nuove Tendenze Psicologia 2004;2:392-412. 